2. Ильин Е. П. Психология спорта/Е. П. Ильин. - СПб.: Питер, 2009. - 352 с.

3. Аурия А. Р. Высшие корковые функции человека и их нарушения при мокальных поражениях мозга (3-е изА.)/А. Р. Аурия. - М.: Академический Проект, 2000. - 512 с.

4. Москвин В.А. Межполушарные асимметрии и индивидуальные различия человека/В.А. Москвин, Н. В. Москвина. - М.: Смысл, 2011.- 368 с.

5. Москвина Н. В. Индивидуальные стили реагирования на факторы стресса/Н. В. Москвина//Теория и практика прикладных и экстремальных видов спорта. - 2010. - № 4 (19). - С. 20-22.

6. Ханин Ю. А. Психология общения в спорте/Ю. А. Ханин. - М.: Физкультура и спорт, 1980. - 208 с.

7. Хомская Е.А. Нейропсихология индивидуальных различий/Е.А. Хомская, И.В. Ефимова, Е. В. БуАыка, Е. В. Ениколопова. - М.: ИзА-во РПА, 1997. - 281 с.

8. Sakano N. Latent left-handedness. Its relation to hemispheric and psychological functions/N. Sakano.Jena: Gustav Fischer Verlag, 1982. - 122 p.

Moskvin Victor Anatolevich, Russian University of Physical Education, Sport, Youth and Tourism Dr.Psych., professor of psychology department of RSUPhCSYT E-mail:1700018v@mail.ru

Moskvina Nina Victorovna, Russian University of Physical Education, Sport, Youth and Tourism Ph.D., associate professor of psychology department of RSUPhCSYT

\title{
Psychophysiology and features volitional regulation sport university students
}

Abstract: The features of volitional functions in 100 students of sports high school at the age of 18 to 25 years. The methods used are: R. Cattell Personality Inventory, a questionnaire diagnosis of volitional personality traits - VPT (Chumakov, M.V.), an indicator of stability and choice of color stimuli and «Map of lateral signs $\gg$. The data revealed the presence of a strong-willed individual characteristics of the regulation of a person related to the peculiarities of functional asymmetries.

Keywords: functional asymmetry, brain, the individual differences, strong-willed regulation, sports psychology

Москвин Виктор Анатольевич, Российский государственный университет физической культуры, спорта, молодежи и туризма д.nсх. н., профессор кафедры психологии РГУФКСМиТ E-mail:1700018v@mail.ru

Москвина Нина Викторовна Российский государственный университет физической культуры, спорта, молодежи и туризма дочент кафедры психологии РГУФКСМиТ

\section{Психофизиология и особенности волевой регуляции у студентов спортивного вуза}

Аннотация: Исследованы особенности волевых функций у 100 студентов спортивного вуза в возрасте от 18 до 25 мет. Использовались методики: мичностный опросник Р. Кеттемла, 
опросник Аиагностики волевых качеств мичности - ВКА (по М.В. Чумакову), показатель устойчивости выбора цветовых стимулов и «Карта матеральных признаков». Аанные выявили наличие индивидуальных особенностей волевой регуляции человека, связанных с особенностями функциональных асимметрий.

Ключевые слова: функциональные асимметрии, мозг, индивидуальные особенности, волевая регуляция, спортивная психология

Введение в проблему. Место понятия «вомя», занимавшего Алительное время центральное поможение в психологических концепциях, в настоящее время все еще весьма неопределенно. Среди исследователей нет еАинства в определении «воли» и связанных с нею понятий «вомевого Аействия», «волевой регуляции», «вомевого усимия».

По В.А. Москвину [3] индивидуальные особенности волевых функций связаны с инАивидуальными стилями самореализации. Это может проявмяться в том, что мица с преоблаАанием признаков мевополушарного Аоминирования (особенно с проявцением парциацьного Аоминирования мевой мобной Аоли) могут Аостигать больших успехов в процессе жизненного самоопреАемения, а Аефицитарность мевополушарных функций можно рассматривать в качестве индивидуальной нейропсихологической преАпосылки развития состояний зависимости (в широком смысле этого слова). Учет инАивидуацьных особенностей волевой регумяции имеет большое значение в психомогии при отборе и подготовки спортсменов высокой квамификации.

Цель: исследование индивидуальных особенностей волевых качеств у миц молодого возраста (на примере студентов спортивного вуза).

Методика. Аля изучения особенностей вомевой регумяции было проведено исследование, в котором приняли участие 90 студентов спортивного вуза в возрасте от 18 до 25 мет.

Исследование проводилось в виде групПового тестирования. Использовались следующие метоАики: мичностный опросник Р. Кеттемла (форма A), опросник Аиагностики волевых качеств мичности - ВКА по М.В. Чумакову [6], показатель устойчивости выбора цветовых стимулов по В.А. Москвину [3; 4] и «Карта матеральных признаков» Аля исследования особенностей функциональных асимметрий [2; 3; 4].
Опросник ВКА предназначен Аля Аиагностики выраженности волевых качеств мичности и применяется Аля испытуемых в возрасте от 18 до 35 мет. В методике содержится 9 шкал: «ответственность », «инициативность», «решительность», «самостоятельность», «выдержка», «настойчивость», «энергичность », «внимательность», «целеустремленность» [6].

Цветовой тест М. Аюшера считается проективным методом и используется Аля опосреАованного изучения мичности (хотя отношение к нему профессиональных психологов до сих пор не явмяется однозначным). В этом исследовании учитывался показатель устойчивости выбора (УВ) цветовых стимулов - по сопоставцению данных первого и второго выборов. При разработке этого показателя преАполагалось, что процесс выбора цветовых стимулов может рассматриваться как модель принятия решения, по которой опосредованно можно судить об особенностях целеобразующих функций испытуемого [3; 4].

Особенности функциональных асимметрий и индивидуальные матеральные профили опредемялись в системе измерений «рука-ухо-глаз» [3; 4]. Учитывацась также проба А. Р. Аурия «перекрест рук», которая отражает парциальное Аоминирование контратеральных мобных отделов мозга по N. Sakano [7].

При анализе весь массив выборки был разАелен на Аве подгруппы - по признаку Аоминантного Аоктя (или парциального Аоминирования контрлатеральных мобных отделов). Были выделены испытуемые с правыми показатемями пробы «перекрест рук» (ППППР) и с мевыми (АПППР). Разделение выборки по Аоминантному моктю было осуществлено не случайно. По А. Р. Аурия [2] третий блок мозга осуществляет программирование, регумяцию и контроль наА протеканием психической Аеятельности. В работах В.А. Москвина было показано, что проба А. Р. Аурия «перекрест рук» позвоцяет не только 
выявмять парциальное Аоминирование мобных отделов и асимметрию третьего блока мозга, но и определить доминирование мобно-ретикумярного ими мобно-лимбического комплексов мозга $[3,4]$.

Статистическая обработка данных исследования проводилась с использованием $U$ - критерия Вилкоксона-Манна-Уитни.

Результаты исследования. Сравнение усреАненных данных по методике ВКА М.В. Чумакова [6] показало, что испытуемые с правыми ПППР (по сравнению с мевыми ПППР) обнаруживают более высокие показатели по шкацам «ответственность $\gg(4,7$ б. и 4,0 б. соответственно, $\mathrm{p}<0,05)$, «инициативность $\gg(4,9$ б. и 4,0 6., $\mathrm{p}<0,05)$, «энергичность $\gg(6,7$ б. и 6,1 б., $\mathrm{p}<0,03)$ и по шкале «целеустремленность » $(6,4$ 6. и 5,6 б. соответственно, $\mathrm{p}<0,05)$.

По факторам опросника Р. Кеттемла были получены следующие результаты. По фактору $\mathrm{F}$ («экспрессивность - слержанность») более высокие значения отмечены в группе Аиц с правыми ПППР - 5,5 баммов, в группе с мевыми ПППР $4,7$ 6. ( $\mathrm{p}<0,03)$, что свидетельствует о большей активности, живости и гибкости поведения испытуемых с правыми ПППР. Значения по фактору $\mathrm{N}$ («наивность - проницательность») ниже в группе миц с правыми ПППР - 5,1 баммов, а в группе с мевыми ПППР они оказались выше - 5,9 6. $(\mathrm{p}<0,03)$.

Аанные теста Аюшера. Испытуемые с правыми ПППР (по сравнению с мевыми ПППР) обнаружили более высокие показатели в восьмицветовом варианте теста Һюшера по показателю устойчивости выбора $(80,7$ б. и 68,5 б. соответственно, $\mathrm{p}<0,04)$. При разработке показателя устойчивости выбора преАполагалось, что процесс выбора цветовых стимумов может рассматриваться как модель деятельности принятия решения, по которой опосреАованно можно суАить об особенностях целеобразующих функций (в виде устойчивости принятых решений).

ОбсужАение результатов. В результате анамиза полученных Аанных было выяснено, что испытуемые с Аоминирующим правым моктем (что отражает парциальное доминирование мевых мобных отделов) по Аанным методики
ВКА М. В. Чумакова [6] обнаруживают более высокие показатели по шкацам «ответственность», «инициативность», «энергичность» и «целеустремленность» Они чаще проявмяют такие качества как живость, энергичность, жизнерадостность (по данным теста Р. Кеттемма).

Также бымо выявлено, что значения по фактору $\mathrm{N}$ в тесте Р. Кеттэмла ( «наивность - проницательность») оказались ниже в группе испытуемых с правыми ПППР — 5,1 баммов, а в группе с мевыми ПППР они оказались выше - 5,9 6. $(\mathrm{p}<0,03)$, что может соответствовать проявмению таких качеств как проницательность, хитрость, расчетливость, утонченность.Э. ГолАберг считает, что правое полушарие более специализировано Амя переработки и анализа новой когнитивной информации, а мевое Аля переработки уже знакомой и рутинной информации [1]. Т. В. Черниговская с соавт. также отмечает, что мица с высокими значениями фактора $\mathrm{N}$ по тесту Р. Кеттемла чаще бывают правополушарными [5]. Анализ показателя устойчивости выбора показывает, что он достоверно выше оказывается у миц с доминированием мевых мобных отделов (у миц с правыми ПППР), что говорит о большей устойчивости принятых планов поведения.

Полученные Аанные показывают, что испытуемые с разными показатемями ПППР по А. Р. $\Lambda$ рия обнаруживают достоверные различия по ряду шкал использованных методик. Это позволяет говорить о наличии индивидуальных особенностей волевой регуляции человека, связанных, в свою очереАь, с индивидуальными профилями матеральности или вариантами сочетаний показателей асимметрии.

Выводы. Аанные подтвержАают имеющееся мнение о наличии асимметрии блоков мозга по А. Р. Аурия, в том числе и третьего блока. Регумяторные аспекты эмоционального реагирования по преимуществу обеспечиваются структурами мобных отделов мевого полушария. Эти положения подтвержАаются Аанными психодиагностических исследований миц с разными катеральными особенностями и тем, что парциальное Аоминирование мевой мобной Аоли (у миц мужского пола) связано с более высокими показателями 
сформированности жизненных целей (целеобразования) и таким психологическим феноменом как «временная перспектива». Полученные результаты могут быть полезны не только Аля развития теории нейропсихомогии и психофизиологии
инАивидуамьных различий, а также практически могут быть использованы Аля Аиагностики инАивидуальных особенностей волевой регумяции в спортивной психологии при поАготовке спортсменов высокой квамификации.

\title{
Список митературы:
}

1. Голдберг Э. УПравмяющий мозг: Аобные Аоли, мидерство и цивилизация/Пер. с англ. А. Булгакова. М.: Смысл, 2003. - 335 с.

2. Аурия А.Р. Основы нейропсихологии. - М.: ИзА-во МГУ, 1973. - 374 с.

3. Москвин В.А. Межполушарные отношения и проблема индивидуальных размичий. - М.: ИзА-во МГУ, 2002.- $288 \mathrm{c}$.

4. Москвин В.А. Межполушарные асимметрии и индивидуальные различия человека/В. А. Москвин, Н.В. Москвина. - М.: Смысл, 2011.- 368 с.

5. Черниговская Т.В., Гаврилова Т.А., Воинов А.В., Стрельников К.Н. Сенсо-моторный и когнитивный матерамьный профиль//Физиология чемовека. - 2005. - Т. 31. - № 2. - С. 35-44.

6. Чумаков М.В. Аиагностика волевых особенностей мичности//Вопр. психологии. - 2006. - № 1.C. $169-178$.

7. Sakano N. Latent left-handedness. Its relation to hemispheric and psychological functions.- Jena: Gustav Fischer Verlag, 1982. - 122 p.

Simonenkova Irina Petrovna, Russian State University of Physical Education, Sport, Youth and Tourism postgraduate student, department of psychology E-mail: irina.simonenkova@gmail.com

\section{High league bench players and starters: differences in group interactions, group cohesion, role acceptance and self-confidence in football teams}

\begin{abstract}
Main staff players differ from bench players in their perceptions and demonstrate different responses. This research compares the situation of bench players with the situation of starters in high league Latvian football teams.

Keywords: bench players, starters, group interactions, group cohesion, role acceptance, selfconfidence

The general purpose of this research is to compare the situation of bench players with the situation of starters in high league football teams. The study covers following topics: group cohesion, the interaction in a team and more specific between bench players and starters, self-confidence, and role acceptance.

A questionnaire was compiled to inquire bench

starters and bench players would respond differently and have different perceptions concerning the research topics.

A supposition can be made that main staff players differ from bench players in their perceptions and demonstrate different responses based on the given aspects.
\end{abstract} players and starters. One could hypothesize that

Participants

\begin{tabular}{|c|c|c|c|c|}
\hline Country & Participants & Average age & Starters & Bench players \\
\hline Latvia & 52 & 24.2 & 33 & 19 \\
\hline
\end{tabular}

